\title{
"CORONAVIRUS" INNOVATIONS IN MEDIA LANGUAGE AND INTERNET COMMUNICATION
}

\author{
Vladislav E. Zamaldinov \\ Nizhny Novgorod Academy of the Ministry of Internal Affairs of Russia, Nizhny Novgorod, Russia \\ Daiki Horiguchi \\ Kyoto University, Kyoto, Japan
}

\begin{abstract}
The article examines the structural features of neologisms associated with coronavirus pandemic based on the texts of mass media and Internet communication. The paper uses such research methods as the continuous sampling method, the general scientific descriptive and analytical method, the methods of wordformation, structural and semantic analysis of neologisms. The authors analyzed the nominal derivatives of conventional (addition, prefix, suffixation, affixation) and occasional (inter-word overlap, graphic hybridization, substitution derivation) methods of word formation in media texts. The key elements of the sociocultural space (virus, quarantine, coronavirus, masks, etc.) that evoke negative associations in the addressee are identified. Having found and analysed nominations with the corona component, the researchers proved that this element tends to demonstrate the features of prefixoid. Neologisms with corona component are critical phenomena, negative changes in the economy, tourism, politics; they denote the living conditions that have developed during the coronavirus infection, etc. It is shown that the vocabulary of the modern Russian language is actively replenished with verbal neologisms, which areused to add expressiveness to media text; they correlate with actual phenomena of public life. The authors conclude that "coronavirus" neologisms participate in creating the expressiveness of the text, reflect reality, and allow journalists to deliver their own opinion. The results of the conducted research contribute to word-formation neology, media linguistics, can be useful to students of philological specialties, lecturers and tutors, as well as to anyone interested in active processes, which occur in the modern Russian language.
\end{abstract}

Key words: word-formation, neologism, media language, Internet-communication, conventional ways of word-formation, occasional ways of word-formation.

Citation. Zamaldinov V.E., Horiguchi D. "Coronavirus" Innovations in Media Language and Internet Communication. Vestnik Volgogradskogo gosudarstvennogo universiteta. Seriya 2. Yazykoznanie [Science Journal of Volgograd State University. Linguistics], 2021, vol. 20, no. 5, pp. 141-152. (in Russian). DOI: https://doi.org/ 10.15688/jvolsu2.2021.5.11

\section{«КОРОНАВИРУСНЫЕ» НОВООБРАЗОВАНИЯ В ЯЗЫКЕ СМИ И ИНТЕРНЕТ-КОММУНИКАЦИИ}

\author{
Владислав Евгеньевич Замальдинов \\ Нижегородская академия МВД России, г. Нижний Новгород, Россия
}

Даики Хоригути

Киотский университет, г. Киото, Япония

Аннотация. В статье на материале текстов СМИ и интернет-коммуникации рассмотрена структура новообразований, связанных с пандемией коронавирусной инфекции. В.Е. Замальдиновым проанализиро- 
ваны именные дериваты, образованные узуальными и неузуальными способами. Выявлены ключевые элементы социокультурного пространства, выраженные такими лексическими единицами, как вирус, карантин, коронавирус, маски и др., вызывающие у адресата отрицательные ассоциации. Д. Хоригути обнаружены и описаны номинации с компонентом корона-: установлено, что они называют явления критического характера, негативные изменения в сфере экономики, туризма, политики, обозначают условия жизни, сложившиеся в период коронавирусной инфекции; показано, что лексика современного русского языка активно пополняется глагольными неологизмами, которые соотносятся с актуальными явлениями общественной жизни и придают экспрессивность медийному тексту. Авторами сделан вывод о том, что «коронавирусные» неологизмы, отражая действительность, участвуют в создании выразительности текста, позволяют журналистам высказывать собственное мнение. Результаты проведенного исследования вносят вклад в словообразовательную неологию, медиалингвистику, могут быть полезны студентам филологических специальностей, преподавателям высших учебных заведений, а также всем интересующимся активными процессами в современном русском языке.

Ключевые слова: словообразование, неологизм, язык СМИ, интернет-коммуникация, узуальные способы словообразования, неузуальные способы словообразования.

Цитирование. Замальдинов В. Е., Хоригути Д. «Коронавирусные» новообразования в языке СМИ и интернет-коммуникации // Вестник Волгоградского государственного университета. Серия 2, Языкознание. 2021. - T. 20, № 5. - C. 141-152. - DOI: https://doi.org/10.15688/jvolsu2.2021.5.11

\section{Введение}

Медийная коммуникация чутко реагирует на все изменения, происходящие в жизни общества. Именно СМИ выражают настроение нации, информируют аудиторию о значимых событиях, воздействуют на сознание адресата и, кроме того, фиксируют различные процессы в языке. По мнению О.С. Иссерс, «медиа в постиндустриальном обществе являются не только посредниками в трансляции информации, но и одним из главных стимулов для формирования социальных норм во всех сферах общественной жизни» [Иссерс, 2019, с. 179].

Главной темой последних двух лет в СМИ и интернет-коммуникации стала мировая эпидемия. Коронавирусная инфекция быстро распространилась за пределы Китая, и сложившаяся в связи с этим ситуация оказала влияние на все сферы деятельности людей. В таких непростых условиях медиатексты стали источником значимой для людей информации. По мнению В.И. Карасика, ее можно разделить на следующие группы сведений: «1) определение заболевания, его история и характеристики; 2) деятельность властей по борьбе с эпидемией; 3) прогнозы специалистов по развитию заболевания; 4) отклики и комментарии пользователей интернета об этом вирусе» [Карасик, 2020, с. 26]. В погоне за сенсацией некоторые журналисты искажают информацию, усиливают панику в обще- стве и извлекают из этого выгоду. Это способствует появлению непреднамеренных ошибок и фейковых новостей. По мнению исследователей, «люди склонны верить такого рода информации, потому что она может спасти от опасности» [Кошкарова, Бойко, 2020, с. 80].

События, связанные с пандемией, не могли не получить отражения в лексике современного русского языка.

\section{Материал и методы исследования}

Источниками фактического материала послужили тексты СМИ и интернет-коммуникации за период с января по июль 2020 года. В данной работе использовались такие методы, как сплошная выборка, общенаучный описательноаналитический метод, методы словообразовательного, структурно-семантического анализа.

Авторы учитывали новейшие достижения лингвистов в изучении актуальных вопросов неологии (см., например: [Зеленин, Буцева, 2021; Козловская, 2020; Минеева, 2020; Северская, 2020; Ярошенко, 2020; и др.]), особенностей языка СМИ и интернет-коммуникации (см., например: [Добросклонская, 2020; Желтухина, 2020; Кормилицына, 2020; Полонский, 2019; и др.]).

\section{Результаты и обсуждение}

Коммуникативное пространство СМИ за короткое время пополнилось новообразовани- 
ями, связанными с пандемией коронавирусной инфекции в мире. Активность употребления таких номинаций способствует их закреплению в сознании аудитории как ключевых элементов социокультурного пространства. Новообразования на базе лексем вирус, карантин, коронавирус, маски, пандемия, эпидемия и др. чаще всего вызывают у носителей языка отрицательные ассоциации, так как соотносятся с болезнью.

Для создания инноваций, отражающих эпидемиологическую ситуацию в мире, журналисты используют узуальные и неузуальные способы словообразования.

Именные дериваты, созданные узуальными способами словообразования. В современных СМИ адресанты употребляют элемент корона-. Номинации с данной частью можно отнести к сложению:

(1) Коронавирус сегодня переиначивают в коронакризис, коронаужас, коронакрах, коронастресс и даже коронасекс ${ }^{1}$ (Еврейский мир. 2020. 29 апр.).

Активное распространение сложных слов с компонентом корона- позволяет предположить, что данный элемент тяготеет к таким префиксоидам, как евро-, кино-, инфо-, бизнес-, нарко-, и сочетается с лексическими единицами различной семантики. В первую очередь отметим новообразования, связанные с масштабным распространением коронавируса:

(2) Когда началась коронаатака, не договорились, как фиксировать эту статистику (Клуб регионов. 2020. 11 июня);

(3) Ранее Finnair сообщила о крупных убытках, возникших во время коронаэпидемии (Postimees. 2020. 12 мая).

Корень корона- также сочетается с наименованиями явлений критического характера, вызванных пандемией:

(4) Коронавойна в Азербайджане продолжается и обретает все более ожесточенные формы (Евразийцы - новая волна. 2020. 31марта).

В медийных текстах адресанты активно используют номинации с элементом корона-, обозначающие условия жизни, сложившиеся в период пандемии:
(5) В наши дни коронажизни нам представляют цифры - статистика жизни и смерти, где жизнь проигрывает от страны к стране (Кавказский узел. 2020. 25 марта);

(6) Коронамеры против коронавируса (подзаголовок) (Караван. 2020. 15 мая).

Коронавирус негативно отразился и на глобальной экономике. Поэтому отдельную группу новообразований составляют номинации, связанные со спекуляцией, безработицей, снижением экономической активности в ряде стран:

(7) Коронабизнес: кто и как зарабатывает на болезни (заголовок)? Пока специалисты борются с распространением коронавируса, находятся люди, которые умудряются заработать на инфекции (Радио Sputnik. 2020. 13 марта);

(8) Коронаэкономика: мир станет другим, но выживет (заголовок) (Инвест-Форсайт. 2020. 16 марта).

Во время эпидемии пострадала также туристическая отрасль. Многие организации, не имея достаточных средств на зарплату сотрудникам, объявили себя банкротами. Поэтому в отдельную группу мы выделим новые производные, связанные с индустрией туризма:

(9) «Коронаотдых». Как белорусские туристы стали «заложниками» ГОА (заголовок) (News.21.by. 2020. 25 марта);

(10) Это тот самый паспорт иммунитета, или коронапаспорт, который обеспечит и возможность передвижения туристов, и безопасность (ExpertTur. 2020. 28 апр.).

В период пандемии в текстах СМИ появились новообразования в сфере политики, реализующие ироническую тональность:

(11) Теперь я навсегда останусь Главным Вирусоносителем. За это уже проголосовали все заразные коронадепутаты, то есть единогласно (Эхо России. 2020. 14 марта);

(12) Начавшуюся в Беларуси президентскую кампанию местные журналисты уже прозвали «коронавыборы» (по аналогии с коронакризисом). А еe неофициальным символом стал домашний тапоккак самое эффективное средство борьбы с тараканами (Planeta. 2020. 28 мая).

В текстах СМИ выявлены сложные неологизмы, второй компонент которых связан с 


\section{МАТЕРИАЛЫ И СООБЩЕНИЯ}

психическими расстройствами и особым эмоциональным состоянием человека:

(13) Коронапсихоз: россияне стали на треть чаще обращаться к психологам (заголовок) (Комсомольская правда. 2020. 14 апр.);

(14) Нынешняя коронаистерика - лучшее время для рассекречивания НЛО (Аргументы и факты. 2020. 18 мая).

Пандемия во многих странах привела к активизации деятельности злоумышленников и дезинформаторов, что подтверждают такие номинации, как короначелители, коронамошенники, коронафейк и др. Их использование способствует усилению паники, усугубляет недоверие читателей к статистике по смертности от коронавирусной инфекции:

(15) Пока граждане, обуреваемые страхом пандемии, скупали традиционные продукты, входящие в паническую корзину, открылся фестиваль коронамошенников и коронацелителей (Правда.Ру. 2020. 21 марта);

(16) Страницы издания просто кишат коронафейками (ВосходИнфо. 2020. 14 апр.).

Дериваты с элементом корона- могут также называть реалии, связанные с новыми технологиями:

(17) Коронагаджеты. Какие устройства придумывают для борьбы с инфекцией (заголовок) (Аргументы и факты. 2020. 5 мая);

(18) На прошлой неделе Google и Apple coвместными усилиями пришли к созданию технологии, позволяющей намного лучше создать так называемое коронаприложение, оповещающее пользователя, если у человека, находившегося с ним поблизости, был диагностирован коронавирус (Postimees. 2020. 26 мая).

Кроме того, с распространением коронавирусной инфекции появились новые реалии и в сферах спорта и здорового образа жизни:

(19) Коронафитнес (заголовок). Директор фитнес-центра «Волга Спорт» Любовь Суслова рассказала, что, в случае введения временного запрета на деятельность фитнес-клубов в регионе, они уйдут в онлайн-режим (Коммерсантъ-Саратов. 2020. 24 марта);

(20) Коронаспорт: Роналду хотят продать, Уимблдон отменили (заголовок) (Радио Sputnik. 2020. 1 апр.);
(21) «Коронадиета»: как не набрать лишний вес в дни карантина (заголовок) (Детали. 2020. 25 марта).

В целом актуализация первого компонента корона- в сложных новообразованиях демонстрирует, насколько изменилось общественное сознание в период пандемии.

Заслуживают внимания и префиксальные дериваты. Словообразовательную активность в текстах СМИ проявляет приставка псевдос семантикой ложности:

(22) Псевдокарантин или Мертвому припарка (заголовок). Ноль случаев коронавирусной инфекции в Харькове и области - неправда, и это уже очевидно каждому (Объектив. 2020. 26 марта);

(23) А вдруг это очередная псевдоэпидемия, разводка «лохов»? (Комсомольская правда. 2020. 9 апр.).

Исследование показывает, что новообразования с препозитивным элементом

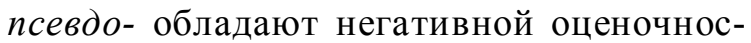
тью, которая усиливается семантикой мотивирующего слова и контекстуальным окружением.

Продуктивность демонстрирует и исконный префикс недо- с семантикой неполноценности. Так, носители языка воспринимают меры по борьбе с коронавирусной инфекцией как недостаточные:

(24) Недосамоизоляция: почему самарцы игнорируют рекомендации по коронавирусу (заголовок) (ВолгаНьюс.рф. 2020. 17 марта);

(25) Майская недоизоляция: четверть ярославцев провели праздник на даче, почти треть жарили шашлыки (заголовок) (Московский комсомолец в Ярославле. 2020. 13 мая).

Журналисты активно создают «вирусные» номинации суффиксальным способом словообразования. Так, продуктивной морфемой в медийном пространстве является суффикс -ец с семантикой «болезнь, характеризующаяся отношением к тому, что названо мотивирующим существительным» (Словарь словообразовательных аффиксов..., с. 326):

(26) Решение выйти из переговоров с ОПЕК обрушило нефть и рубль как раз тогда, когда в мире и России случился полный коронавирусец (Новая газета. 2020. 2 апр.). 
На наш взгляд, подобные номинации с суффиксом -ец имеют сходство с обсценными выражениями, обладают отрицательной экспрессией. Новообразования усиливают вербальную агрессию, шокируют адресата, создают нежелательный эмоциональный эффект. «Инновации на -ец, как правило, выступают в составе модели “полный + ..." как эвфемистическая замена нецензурного выражения» [Ильясова, 2014, с. 61]. Употребление агрессивных номинаций в медийном тексте не только не способствует эффективному общению с адресатом, но и приводит к коммуникативным неудачам.

Заслуживают внимания новообразования с суффиксом -ищ(е) с размерно-оценочным значением, которые обладают разговорной окраской и придают медийному тексту ироническую тональность:

(27) Карантинище! В Индии «заперли» 1,3 миллиарда жителей (заголовок). В Индии будет введен всеобщий трехнедельный карантин в связи с коронавирусом (BB.lv. 2020. 25 марта);

(28) Вспомните, вирусище толком не вышел за пределы Китая, а Дональд Трамп, Борис Джонсон, Эммануэль Макрон и Ангела Меркель как по команде заорали, что жертв будет очень много и грядут трудные времена! (Экспресс газета. 2020. 3 апр.).

Интерес представляют номинации, созданные с помощью аффиксоидации - самостоятельного способа словопроизводства (см., например: [Коряковцева, 2016, с. 128]). Так, значительную роль в языке СМИ и интернеткоммуникации стали играть префиксоиды. Активность в медийных текстах проявляет исконный префиксоид лже- с семантикой неистинности:

(29) Назначение тюменского ректора министром, лжекарантин в школах, «детский» скандал Водонаевой: самые важные итоги за 22 января (заголовок) (Наша газета. 2020. 22 янв.);

(30) Лжетаблетки и псевдовакцины. Как аферисты наживаются на коронавирусе (заголовок) (Life.ru. 2020.2 февр. ).

Анализ языкового материала показал, что номинации с префиксоидом лже- обладают негативной оценочностью, которая усиливается контекстом. Новообразования с пре- фиксоидом лже- отражают неистинность событий современной действительности, распространение фальшивых ценностей (подробнее об этом см.: [Замальдинов, 2020]).

В медийных текстах нами обнаружены новообразования с префиксоидом кибер-:

(31) Россиян предупредили о начале «киберкоронав ируса» (заголовок). Пандемия коронавируса привела к активизации мошенничества в интернете, злоумышленники воспользовались нарастающим беспокойством россиян (Lenta.ru. 2020. 17 марта);

(32) Человечеству сегодня помимо пандемии коронавируса угрожает так называемая киберпандемия, спровоцированная негативным развитием цифровых технологий (РИА Новости. 2020. 7 апр.).

Научно-технический прогресс повлек за собой необходимость создания новых слов. Они используются для номинации компьютерных реалий, имеют негативную оценочность, которая обусловлена мотивирующей семантикой и поддержана контекстом.

Помимо префиксоидации, в медийных текстах представлена и суффиксоидация. Так, можно предположить, что к суффиксоидам тяготеет элемент -демия с семантикой масштабного распространения чего-либо нежелательного:

(33) В мессенджеры ежедневно сыплется всякая ахинея про «фейковирус» и «паникодемию»и распространяют ее самые разные люди (Вечерняя Москва. 2020. 16 мая);

(34) Фейкодемия: люди, будьте бдительны! (заголовок) (Sputnik Южная Осетия. 2020. 30 мая).

Итак, журналисты активно используют в языке СМИ и интернет-коммуникации именные дериваты, созданные с помощью таких узуальных способов словообразования, как сложение, префиксация, суффиксация, аффиксоидация. Подобные новообразования обладают оценочностью, придают тексту публикации ироническую тональность, отражают изменения в жизни людей в период пандемии.

Именные дериваты, созданные неузуальными способами словообразования. В медийной коммуникации востребованы и окказиональные способы деривации. По словам Е.А. Земской, «если неузуальное словообразование было характерно ранее пре- 


\section{МАТЕРИАЛЫ И СООБЩЕНИЯ}

имущественно для языка художественной литературы и разговорной речи, то в языке газет доперестроечного периода оно не было столь широко распространенным явлением. В наше время газеты пестрят окказионализмами» [Земская, 2000, с. 128]. Распространенным неузуальным способом, используемым для создания окказионализмов, в нашем материале является междусловное наложение, под которым мы понимаем такое соединение двух слов в одно, когда полностью сохраняются оба соединяющихся слова, но определенный фонемный отрезок нового слова принадлежит одновременно обеим мотивирующим частям (см. об этом: [Улуханов, 1996, c. 52]). Приведем примеры.

(35) Спецкор «Ђ» исследовал коронавирусский характер (Коммерсантъ. 2020. 21 марта)

\section{(коронавирус + русский $\rightarrow$ коронавирус- ский).}

В период пандемии глобальное распространение в языке СМИ получила номинация ковидиот (covidiot) и ее производные:

(36) Причем эта вторая пандемия - ковидиотская, тоже доводит до смертей (Конт. 2020. 26 марта)

$($ ковид + идиотская $\rightarrow$ ковидиотская).

В медийном пространстве при междусловном наложении возможны и формальные замены графем в номинациях:

(37) Банковские карантии (заголовок). 23 апреля президент России Владимир Пугин встретился с банкирами, которым рассказал, что деньги у них, чтобы и самим кризис пережить, и всем остальным его облегчить, есть (Коммерсанть. 2020. 24 апр.)

(каранти $($ н) + (г)арантии $\rightarrow$ карантии).

С помощью новообразований, созданных путем междусловного наложения, журналисты выражают иронию и сарказм, вызывают эмоциональную реакцию у читателя. Однако адресантам необходимо помнить о том, что ирония может свидетельствовать о вербальной агрессии, усиливать эффект сказанного / написанного, вступать в контраст с трагической обстановкой в мире. «Не всем под силу филигранно владеть тонкой иронией, под пером некоторых журнали- стов она превращается в средство речевой агрессии, способ поиздеваться над кем-нибудь» [Самусевич, 2017, с. 46].

В медийных текстах встречаются «вирусные» новообразования, созданные с помощью графической гибридизации, представляющей собой процесс создания языковых единиц, в которых графически выделяется сегмент. В массмедиа активно используется такой вид графической гибридизации, как полиграфиксация. В полиграфиксатах одна часть номинации передается латинской графикой, а другая - кириллической:

(38) В понедельник с 10.00 до 20.00 в группе в соцсети ВКонтакте «БЕZООМный ЗВОНОК» всех участников ждет насыщенная программа (Пермский информационный портал. 2020. 24 мая);

(39) Выпускное беZOOMие (заголовок). Последний звонок онлайн (Частный корреспондент. 2020.27 мая).

Подобные графические гибриды привлекают внимание адресатов, вносят эпатажноигровое начало в текст, создают экспрессивность. Как отмечает Т.В. Попова, «в русскоязычной же прессе наоборот, полиграфиксация... очень популярна, что говорит о значительном влиянии Запада на русскую печатную прессу» [Попова, 2018, с. 254].

В языке СМИ функционируют новообразования, созданные с помощью заменительной деривации, при которой происходит замена корневой или другой неформантной части в узуальной сложной лексеме:

(40) Маскозакидательские настроения (заголовок). Масштабное распространение масочного режима в России, который уже ввели около 70 субъектов, привело к активизации импорта защитных изделий (Коммерсантъ. 2020. 7 мая) - ср. исходное шапкозакидательские (настроения);

(41) Регулирование вакцинообразования (заголовок). Одна из главных интриг мировой повестки на ближайшие месяцы - кто и когда сможет разработать вакцину от коронавируса (Коммерсанть, 07.05.2020) - ср. исходное (регулирование) иенообразования.

Наш материал показывает, что с помощью заменительной деривации чаще всего образуются имена существительные и прила- 
гательные, позволяющие журналистам выразить собственное мнение, усиливающие ироническую экспрессию.

Глагольные новообразования, созданные узуальными способами деривации, в языке СМИ и интернет-коммуникации. Лексическая система современного русского языка активно пополняется не только именными, но и глагольными дериватами. Подобные номинации придают динамику, выразительность и необычность медийному тексту. Кроме того, новые глагольные производные позволяют выявить актуальные способы словообразования, проследить развитие деривационной системы современного русского языка.

При создании глагольных новообразований адресанты широко используют возможности такого способа деривации, как сложение. Одним из глаголов, актуализировавшихся в период пандемии, является глагол самоизолироваться. Сложные глаголы в русском языке - это редкие дериваты, за исключением глаголов на caм-, которые на современном этапе развития языка употребляются в основном только с постфиксом -ся [Гращенков, 2017, с. 27]. В нашем материале встречается также глагол самоизолировать. Он выражает каузативность действия, то есть принудительный характер самоизоляции:

(42) Россиян самоизолировали в рамках закона (заголовок) (Рамблер. 2020. 20 сент.).

В условиях пандемии актуальность приобретают префиксальные производные. Довольно часто их можно наблюдать в заголовках различных публикаций. Так, с помощью префикса недо- журналисты обозначают неполноценность соблюдения режима самоизоляции:

(43) Но пока еще есть пензенцы, которые самоизолировались, самоизолировались - да так и недосамоизолировались. Они гуляют без надобности и не носят маски (Первый пензенский портал, 03.04.2020).

Продолжительная самоизоляция неблагоприятно влияет на психическое состояние общества. Поэтому в языке СМИ мы обнаружили производные с приставками, привносящими в номинацию значение интенсивности:
(44) Некоторые брянцы так пересамоизолировались, что не пускают во двор даже мусоровозы (Город32. 2020. 1 апр.);

(45) «Досамоизолировался»: полиция ищет стрелявшего из окна в ЖК «Цветы» (заголовок) (Репортер-НН. 2020. 6 апр.).

По аналогии с лексемами nосидеть, потусоваться при помощи префикса по- самоизоляция может восприниматься как приятное времяпрепровождение:

(46) Алкогольная самоизоляция (заголовок) 33-летняя гражданка Ш. пригласила друзей вместе посамоизолироваться. Вечеринка удалась - гости выпивали вместе с хозяйкой, поднимали друг другу настроение (Zatosarov.ru. 2020. 29 апр.).

Кроме того, в медийном дискурсе зафиксировано такое префиксальное новообразование, как прокарантинить:

(47) «Прокарантинили эпидемию». Бойко советует властям восстановить экономические связи с РФ (заголовок) (Альтернатива. 2020. 9 июня);

Нередко в медийных текстах встречаются и глагольные новообразования, созданные с помощью суффиксации:

(48) Часть сотрудников по своему желанию уехали «карантинить» домой, а остальных мы обеспечили работой (Деловой Петербург. 2020. 7 июня).

В языке СМИ и интернет-коммуникации востребованы такие узуальные способы создания глагольных новообразований, как сложение, префиксация и суффиксация.

\section{Заключение}

Мировая эпидемия привнесла в современный русский язык большое количество словообразовательных неологизмов. Такие новообразования создаются журналистами с помощью узуальных (сложение, префиксация, суффиксация, аффиксоидация) и неузуальных (междусловное наложение, графическая гибридизация, заменительная деривация) способов словопроизводства. «Коронавирусные» номинации придают тексту экспрессивность и оценочность, отражают действительность, позволяют авторам статей высказывать собственное мнение. Можно предположить, что с окончанием эпидемии 
многие из этих дериватов выйдут из употребления, останутся только ключевые слова - коронавирус и Covid - как напоминание об эпохе болезни.

\section{ПРИМЕЧАНИЕ}

${ }^{1}$ В анализируемых примерах орфография и пунктуация источника сохранены.

\section{СПИСОК ЛИТЕРАТУРЫ}

Гращенков П. В., 2017. Как нарушить три запрета: немного о русских глаголах на сам-...-ся // Вопросы языкознания. № 4. С. 25-32. DOI: 10.31857/s0373658x0001019-9.

Добросклонская Т. Г., 2020. Медиалингвистика: теория, методы, направления. Москва : КДУ ; Добросвет. 178 с. DOI: 10.31453/kdu. ru.91304.0107.

Желтухина М. Р., 2020. Аксиологическая медиатрансляция: социум - культура - политика // Русский язык за рубежом. № 4 (281). С. 68-73.

Замальдинов В. Е., 2020. Когнитивный аспект анализа новообразований стандартной словообразовательной структуры в медийном пространстве // Новые горизонты русистики. № 10. C. 46-51.

Зеленин А. В., Буцева Т. Н., 2021. Лексико-семантические и словообразовательные особенности наименований лиц в период пандемии коронавируса // Русский язык в школе. Т. 82, № 1.C. 74-85. DOI: 10.30515/0131-6141-2021-82$1-74-85$.

Земская Е. А., 2000. Активные процессы современного словопроизводства // Русский язык конца ХХ столетия (1985-1995) / отв. ред. Е. А. Земская. М. : Яз. рус. культуры. С. 90-141.

Ильясова С. В., 2014. Игровые способы и приемы выражения социальной оценочности в языке современных российских СМИ // Политическая лингвистика. № 1 (47). С. 60-64.

Иссерс О. С., 2019. Массовая речевая культура в аспекте медиатизации социальных коммуникаций // Вестник Новосибирского государственного университета. Серия: История, филология. Т. 18, № 6. C. 177-187. DOI: 10.25205/ 1818-7919-2019-18-6-177-187.

Карасик В. И., 2020. Эпидемия в зеркале медийного дискурса: факты, оценки, позиции // Политическая лингвистика. № 2 (80). С. 25-34. DOI: $10.26170 / \mathrm{pl} 20-02-02$.

Козловская Н. В., 2020. О новых объектах описания в современной неографии (к постановке про- блемы) // Актуальные проблемы преподавания филологических дисциплин : материалы докл. и сообщ. XXV Междунар. науч.-метод. конф. (Санкт-Петербург, 7 февр. 2020 г.). СПб. : С.-Петерб. гос. ун-т пром. технологий и дизайна. С. 29-35.

Кормилицына М. А., 2020. Массмедиа как основной фактор изменений в культуре человека информационной эпохи // Личность - Язык Культура : материалы VII Bсерос. науч.-практ. конф. (Саратов, 27-28 нояб. 2019 г.). Саратов : Наука. С. 13-20.

Коряковцева Е. И., 2016. Очерки о языке современных славянских СМИ (семантико-словообразовательный и лингвокультурологический аспекты). Siedlce : Instytut Filologii Polskiej i Lingwistyki Stosowanej. $152 \mathrm{c}$.

Кошкарова Н. Н., Бойко Е. С., 2020. Фейк, я тебя знаю: лингвистические механизмы распознавания ложной информации // Политическая лингвистика. № 2 (80). С. 77-82. DOI: 10.26170/ pl20-02-08.

Минеева 3. И., 2020. Неодериваты в русском языке эпохи пандемии // Новые слова и словари новых слов. 2020 : сб. науч. ст. СПб. : Ин-т лингв. исслед. РАН. С. 166-176.

Полонский А. В., 2019. Медийный текст как феномен современной культуры // Тексты нового века : материалы Межрегион. круглого стола (Орел, 27-28 февр. 2019 г.). Орел : Орл. гос. ин-т культуры. С. 31-34.

Попова Т. В., 2018. Новое в изучении графодеривации // Лингвистика креатива-4 : коллектив. моногр. / под ред. Т. А. Гридиной. Екатеринбург : Урал. гос. пед. ун-т. С. 229-269.

Самусевич О. М., 2017. Феномен речевой агрессии в белорусской прессе // Медиалингвистика. № 2(17). C. 41-51.

Северская О. И., 2020. Ковидиоты на карантикулах: коронавирусный словарь как диагностическое поле актуальных дискурсивных практик // Коммуникативные исследования. Т. 7, № 4. C. 887-906. DOI: 10.24147/2413-6182.2020.7(4). 887-906.

Улуханов И. С., 1996. Единицы словообразовательной системы русского языка и их лексическая реализация. М. : Рус. слов. $221 \mathrm{c}$.

Ярошенко Н. А., 2020. Пандемия COVID-19 в зеркале языка: лексико-семантические группы сложных неономинаций лица // Донецкие чтения 2020: образование, наука, инновации, культура и вызовы современности : материалы V Междунар. науч. конф. (Донецк, 17-18 нояб. 2020 г.) / под общ ред. С. В. Беспаловой. Донецк : Донец. нац. ун-т. C. $145-149$. 


\section{ИСТОЧНИКИ}

Альтернатива - Альтернатива : интернет-СМИ. URL: http://alternatio.org.

Аргументы и факты - Аргументы и факты : газета. URL: https://aif.ru.

Вечерняя Москва - Вечерняя Москва : интернетCМИ. URL: https://vm.ru.

ВолгаНьюс. $ф$ - ВолгаНьюс.рф : интернет-СМИ. URL: https://volga.news.

ВосходИнфо - ВосходИнфо : интернет-СМИ. URL: http://voskhodinfo.su.

Город32 - Город32 : интернет-СМИ. URL: http:// go32.ru.

Деловой Петербург - Деловой Петербург : газета. URL: https://www.dp.ru.

Детали - Детали : интернет-CMИ. URL: https:// detaly.co.il.

Евразийць - новая волна - Евразийцы - новая волна : интернет-СМИ. URL: http://www.enwfond.ru.

Еврейский мир-Еврейский мир : газета. URL: http:// evreimir.com

Инвест-Форсайт - Инвест-Форсайт : журнал. URL: https://www.if24.ru.

Кавказский узел-Кавказский Узел : интернет-СМИ. URL: https://www.kavkaz-uzel.eu.

Караван - Караван : интернет-СМИ. URL: https:// www.caravan.kz.

Клуб регионов - Клуб регионов : интернет-СМИ. URL: http://club-rf.ru.

Коммерсанть - Коммерсанть : газета. URL: https:// www.kommersant.ru.

Коммерсанть-Саратов- Коммерсантъ-Саратов : газета. URL: https://www.kommersant.ru.

Комсомольская правда - Комсомольская правда : газета. URL: https://www.kp.ru.

Конт - Конт : интернет-СМИ. URL: https://cont.ws.

Московский комсомолеи в Ярославле - Московский комсомолец в Ярославле : газета. URL: https://yar.mk.ru.

Нама газета - Наша газета : интернет-CMИ. URL: https://ng72.ru.

Новая газета - Новая газета : газета. URL: https:// novayagazeta.ru.

Объектив - Объектив : интернет-CMИ.URL: https:// www.objectiv.tv.

Первый пензенский портал - Первый пензенский портал : интернет-СМИ. URL: https://1pnz.ru.

Пермский информационный портал - Пермский информационный портал: интернет-СМИ. URL: https://59i.ru.

Правда.Pу - Правда.Ру : интернет-СМИ. URL: https://www.pravda.ru.

Радио Sputnik - Радио Sputnik : сайт радиостанции. URL: https://radiosputnik.ria.ru.
Рамблер - Рамблер : интернет-СМИ. URL: https:// news.rambler.ru.

Pепортер-НН-Репортер-НН : интернет-СMИ. URL: https://reporter-nn.ru.

РИА Новости - РИА Новости : интернет-СМИ. URL: https://ria.ru.

Частный корреспондент - Частный корреспондент : интернет-CMИ. URL: http://www. chaskor.ru.

Экспресс газета - Экспресс газета : интернет-СМИ. URL: https://www.eg.ru.

Эхо России - Эхо России : сайт радиостанции. URL: https://ehorussia.com/new.

BB.lv-BB.lv : интернет-CMИ. URL: https://bb.lv.

ExpertTur - ExpertTur : интернет-CMИ. URL: https:// experttur.com.

Lenta.ru - Lenta.ru : интернет-CMИ. URL: https:// lenta.ru.

Life.ru - Life.ru : интернет-CMИ. URL: https://ife.ru.

News.21.by - News.21.by : интернет-СМИ. URL: https://news.21.by.

Planeta - Planeta : интернет-CМИ. URL: https:// planeta.press.

Postimees - Postimees : интернет-CMИ. URL: https:// rus.postimees.ee.

Sputnik Южная Осетия - Sputnik Южная Осетия : интернет-СМИ. URL: https://sputnik-ossetia.ru.

Zatosarov.ru - Zatosarov.ru : интернет-СМИ. URL: http://zatosarov.ru.

\section{СЛОВАРЬ}

Лопатин В. В., Улуханов И. С. Словарь словообразовательных аффиксов современного русского языка. М. : Азбуковник, 2016. 812 с.

\section{REFERENCES}

Grashchenkov P.V., 2017. Kak narushit tri zapreta: nemnogo o russkikh glagolakh na sam-...-sja [How to Break Three Prohibitions at a Time: Some Remarks on Russian Verbs with sam-...-sia]. Voprosy yazykoznaniya [Topics in the Study of Language], no. 4, pp. 25-32. DOI: 10.31857/ s0373658x0001019-9.

Dobrosklonskaya T.G., 2020. Medialingvistika: teoriya, metody, napravleniya [Media Linguistics: Theory, Methods, Directions]. Moscow, KDU Publ., Dobrosvet Publ. 178 p. DOI 10.31453/kdu. ru. 91304.0107.

Zheltukhina M.R., 2020. Aksiologicheskaya mediatranslyatsiya: sotsium - kultura politika [Axiological Media Broadcasting: Society - Culture - Politics]. Russkiy yazyk 
za rubezhom [Russian Language Abroad], no. 4 (281), pp. 68-73.

Zamaldinov V.E., 2020. Kognitivnyy aspekt analiza novoobrazovaniy standartnoy slovoobrazovatelnoy struktury $\mathrm{v}$ mediynom prostranstve [Cognitive Aspect of the Analysis of Innovations of the Standard Word-formation Structure in the Media Space]. Novye gorizonty rusistiki [New Horizons of Russian Studies], no. 10, pp. 46-51.

Zelenin A. V., Buceva T. N., 2021. Leksikosemanticheskie i slovoobrazovatelnye osobennosti naimenovaniy lits $\mathrm{v}$ period pandemii koronavirusa [Lexical Semantic and Derivational Features of the Names of Persons During the Coronavirus Pandemic]. Russkiy yazyk $v$ shkole [Russian Language at School], vol. 82, no. 1, pp. 74-85. DOI: 10.30515/0131-61412021-82-1-74-85.

Zemskaya E.A., 2000. Aktivnye processy sovremennogo slovoproizvodstva [Active Processes in the Modern Word Derivation]. Zemlyanskaya E.A., ed. Russkiy yazyk kontsa XX stoletiya (1985-1995) [Russian Language of the End of the $20^{\text {th }}$ Century (1985-1995)]. Moscow, Yazyki russkoy kultury Publ., pp. 90-141.

Ilyasova S.V., 2014. Igrovye sposoby i priemy vyrazheniya socialnoy otsenochnosti $v$ yazyke sovremennykh rossiyskih SMI [Playful Ways and Means of the Social Evaluation Expression in the Language of the Modern Russian Mass Media]. Politicheskaya lingvistika [Political Linguistics], no. 1 (47), pp. 60-64.

Issers O.S., 2019. Massovaya rechevaya kultura v aspekte mediatizatsii socialnykh kommunikatsiy [Mass Speech Culture in Terms of Social Communications Mediatization]. Vestnik Novosibirskogo gosudarstvennogo universiteta. Seriya: Istoriya, filologiya [Vestnik NSU. Series: History and Philology], vol. 18, no. 6, pp. 177187.DOI: 10.25205/1818-7919-2019-18-6-177-187.

Karasik V.I., 2020. Epidemiya v zerkale mediynogo diskursa: fakty, otsenki, pozitsii [Epidemic in the Mirror of Media Discourse: Facts, Evaluations, Positions]. Politicheskaya lingvistika [Political Linguistics], no. 2 (80), pp. 25-34. DOI: 10.26170/ p120-02-02.

Kozlovskaya N.V., 2020. O novykh obyektakh opisaniya $\mathrm{V}$ sovremennoy neografii (k postanovke problemy) [On the Problem of New Objects of Description in Modern Neography]. Aktualnye problemy prepodavaniya filologicheskikh distsiplin: materialy dokl. i soobshch. XXV Mezhdunar. nauch-metod. konf. (Sankt-Peterburg, 7 fevr. 2020 g.) [Actual Problems of Teaching Philological Disciplines. Materials of Reports and Reports of the $25^{\text {th }}$ International Scientific and Methodological Conference (Saint Petersburg, February 7, 2020)]. Saint Petersburg, Sankt-Peterburgskiy gosudarstvennyy universitet promyshlennyykh tekhnologiy i dizayna, pp. 29-35.

Kormilitsyna M.A., 2020. Massmedia kak osnovnoy faktor izmeneniy $\mathrm{v}$ kulture cheloveka informatsionnoy epokhi [Mass Media As the Main Factor in the Culture of the Digital Age Person]. Lichnost - Yazyk - Kultura: materialy VII Vseros. nauch.-prakt. konf. (Saratov, 27 28 noyab. 2019 g.) [Personality-LanguageCulture. Materials of the $7^{\text {th }}$ All-Russian Scientific and Practical Conference (Saratov, November 2728, 2019)]. Saratov, Nauka Publ., pp. 13-20.

Koryakovceva E.I., 2016. Ocherki o yazyke sovremennykh slavyanskikh SMI (semantikoslovoobrazovatelnyj i lingvokulturologicheskiy aspekty) [Essays on the Language of Modern Slavic Media (Semantic-Word-Formation and Linguoculturological Aspects)]. Siedlce, Institute of Polish Philology and applied linguistics. $152 \mathrm{p}$.

Koshkarova N.N., Boyko E.S., 2020. Feyk, ya tebya znayu: lingvisticheskie mekhanizmy raspoznavaniya lozhnoy informatsii [Fake, I Know You: Linguistic Tools to Distinguish Mendacious Information]. Politicheskaja lingvistika [Political Linguistics], no. 2 (80), pp. 77-82. DOI: 10.26170/pl20-02-08.

Mineeva Z.I., 2020. Neoderivaty v russkom yazyke epokhi pandemii [New Derivatives in the Russian Language of the Pandemic Era]. Novye slova $i$ slovari novyh slov. 2020: sb. nauch. st. [New Words and Dictionaries of New Words. 2020. Collection of Scientific Articles]. Saint Petersburg, Institut lingvisticheskikh issledovaniy RAN, pp. 166-176.

Polonskiy A.V., 2019. Mediynyy tekst kak fenomen sovremennoy kultury [Media Text As Phenomenon of Modern Culture]. Teksty novogo veka: materialy Mezhregion. kruglogo stola (Orel, 27-28 fevr. 2019 g.) [Texts of the New Century. Materials of the Interregional Round Table(Orel, February27-28, 2019]. Orel, Orlovskiy gosudarstvennyy institut kultury, pp. 31-34.

Popova T.V., 2018. Novoe vizuchenii grafoderivatsii [New in the Study of Graphoderus]. Gridina T.A., ed. Lingvistika kreativa-4 [Creative Linguistics-4]. Yekaterinburg, Uralskiy gosudarstvennyy pedagogicheskiy universitet, pp. 229-269.

Samusevich O.M., 2017. Fenomen rechevoy agressii v belorusskoy presse [Phenomenon of Speech Aggression in the Belarusian Press]. Medialingvistika [Media Linguistics], no. 2(17), pp. 41-51. 
Severskaya O.I., 2020. Kovidioty na karantikulakh: koronavirusnyy slovar kak diagnosticheskoe pole aktualnykh diskursivnykh praktik [Covidiots on Coronacation: Coronaviral Lexicon As a Diagnostic Field for Actual Discoursive Practices]. Kommunikativnye issledovaniya [Communication Studies], vol. 7 , no. 4, pp. 887-906. DOI: $10.24147 / 2413$ 6182.2020.7(4). 887-906.

Uluhanov I.S., 1996. Edinitsy slovoobrazovatelnoy sistemy russkogo yazyka i ikh leksicheskaya realizatsiya [Units of the Word-Formation System of the Russian Language and Their Lexical Implementation]. Moscow, Russkie slovari Publ. $221 \mathrm{p}$.

Yaroshenko N.A., 2020. Pandemiya COVID-19 v zerkale yazyka: leksiko-semanticheskie gruppy slozhnykh neonominaciy litsa [The COVID19 Pandemic in the Mirror of Language: Lexical and Semantic Groups of Complex Facial Neonominations]. Bespalova S.V., ed. Doneckie chteniya 2020: obrazovanie, nauka, innovatsi, kultura $i$ vyzovy sovremennosti: materialy V Mezhdunar. nauch. konf. (Donetsk, 17-18 noyab. 2020 g.) [Donetsk Readings 2020: Education, Science, Innovation, Culture and Modern Challenges. Materials of the $5^{\text {th }}$ International Scientific Conference (Donetsk, November 1718, 2020)]. Donetsk, Donetskiy natsionalnyy universitet, pp. 145-149.

\section{SOURCES}

Alternativa: internet-SMI[Alternative. Online Media]. URL: http://alternatio.org.

Argumenty $i$ fakty: gazeta [Arguments and Facts. Newspaper]. URL: https://aif.ru.

Vechernyaya Moskva: internet-SMI [Vechernyaya Moskva. Online Media]. URL: https://vm.ru.

VolgaNyus.rf: internet-SMI [Volganyus. RF. Online Media]. URL: https://volga.news.

VoskhodInfo: internet-SMI [Sunrise info. Online Media]. URL: http://voskhodinfo.su.

Gorod32: internet-SMI [City 32. Online Media]. URL: http://go32.ru.

Delovoy Peterburg: gazeta [Delovoy Peterburg. Newspaper]. URL: https://www.dp.ru.

Detali: internet-SMI [Details. Online Media]. URL: https://detaly.co.il.

Evraziytsy - novaya volna: internet-SMI [Eurasians the New Wave. Online Media]. URL: http:// www.enw-fond.ru.

Evreyskiy mir: gazeta [Jewish World. Newspaper]. URL: http://evreimir.com.
Invest-Forsayt: zhurnal [Invest-Foresight. Journal]. URL: https://www.if24.ru.

Kavkazskiy uzel: internet-SMI [Caucasian Knot. Online Media]. URL: https://www.kavkaz-uzel.eu.

Karavan: internet-SMI [Caravan. Online Media]. URL: https://www.caravan.kz.

Klub regionov: internet-SMI [Club of Regions. Online Media]. URL: http://club-rf.ru.

Kommersant: gazeta [Kommersant. Newspaper]. URL: https://www.kommersant.ru.

Kommersant-Saratov: gazeta [KommersantSaratov. Newspaper]. URL: https://www. kommersant.ru.

Komsomolskaya pravda: gazeta [Komsomolskaya Pravda. Newspaper]. URL: https://www.kp.ru.

Kont: internet-SMI [CONT. Online Media]. URL: https://cont.ws.

Moskovskiy komsomolets v Yaroslavle: gazeta [Moskovsky Komsomolets in Yaroslavl. Newspaper]. URL: https://yar.mk.ru.

Nasha gazeta: internet-SMI [NashaGazeta. Online Media]. URL: https://ng72.ru.

Novaya gazeta: gazeta [Novaya Gazeta. Newspaper]. URL: https://novayagazeta.ru.

Obyektiv: internet-SMI [Objective. Online Media]. URL: https://www.objectiv.tv.

Pervyy penzenskiy portal: internet-SMI [First Penza portal. Online Media]. URL: https://1pnz.ru.

Permskiy informatsionnyy portal: internet-SMI [Perm Information Portal. Online Media]. URL: https:// 59i.ru.

Pravda.Ru: internet-SMI [Truth.Ru. Online Media]. URL: https://www.pravda.ru.

Radio Sputnik: sayt radiostantsii [Radio Sputnik. Website of the Radio Station]. URL: https:// radiosputnik.ria.ru.

Rambler: internet-SMI [Rambler. Online Media]. URL: https://news.rambler.ru.

Reporter-NN: internet-SMI [Reporter-NN. Online Media]. URL: https://reporter-nn.ru.

RIA Novosti: internet-SMI [RIA Novosti. Online Media]. URL: https://ria.ru.

Chastnyy korrespondent: internet-SMI [Private Correspondent. Online Media]. URL: http:// www.chaskor.ru.

Ekspress gazeta: internet-SMI [Express Newspaper. Online Media]. URL: https://www.eg.ru.

Ekho Rossii: sayt radiostantsii [The Echo of Russia. Website of the Radio Station]. URL: https:// ehorussia.com/new.

BB.lv: internet-SMI [BB.lv. Online Media]. URL: https:// bb.lv.

ExpertTur: internet-SMI [Expertur. Online Media]. URL: https://experttur.com.

Lenta.ru: internet-SMI[Lenta.ru. Online Media]. URL: https://lenta.ru. 


\section{МАТЕРИАЛЫ И СООБЩЕНИЯ}

Life.ru: internet-SMI [Life.ru. Online Media]. URL: https://life.ru.

News.21.by: internet-SMI[News.21.by. Online Media]. URL: https://news.21.by.

Planeta: internet-SMI [Planeta. Online Media]. URL: https://planeta.press.

Postimees: internet-SMI [Postimees. Online Media]. URL: https://rus.postimees.ee.

Sputnik Yuzhnaya Osetiya: internet-SMI [Sputnik South Ossetia. Online Media]. URL: https:// sputnik-ossetia.ru.
Zatosarov.ru: internet-SMI [Zatosarov.ru. Online Media]. URL: http://zatosarov.ru.

\section{DICTIONARY}

Lopatin V.V., Uluhanov I.S. Slovar slovoobrazovatelnykh affiksov sovremennogo russkogo yazyka [Dictionary of Word-Forming Affixes of Modern Russian]. Moscow, Azbukovnik Publ., 2016. 812 p.

\section{Information About the Authors}

Vladislav E. Zamaldinov, Candidate of Sciences (Philology), Senior Lecturer, Department of Foreign Language and Speech Culture, Nizhny Novgorod Academy of the Ministry of Internal Affairs of Russia, Ankudinovskoe Shosse, 3, 603950 Nizhny Novgorod, Russia, zvlad-nn@yandex.ru, https://orcid.org/0000-0003-4513-3571

Daiki Horiguchi, Doctor of Sciences (Philology), Associate Professor, Graduate School of Humanities and Environmental Studies, Kyoto University, 606-8501 Yoshida-honmachi, Sakyo-ku, Kyoto, Japan, horiguchi.daiki.6x@kyoto-u.ac.jp, https://orcid.org/0000-0003-0724-6209

\section{Информация об авторах}

Владислав Евгеньевич Замальдинов, кандидат филологических наук, старший преподаватель кафедры иностранного языка и культуры речи, Нижегородская академия МВД России, Анкудиновское шоссе, 3, 603950 г. Нижний Новгород, Россия, zvlad-nn@yandex.ru, https://orcid.org/0000-0003-4513-3571

Даики Хоригути, доктор филологических наук, доцент Высшей школы гуманитарных и экологических исследований, Киотский университет, 606-8501 Йошида-хонмачи, Сакио-ку, г. Киото, Япония, horiguchi.daiki.6x@kyoto-u.ac.jp, https://orcid.org/0000-0003-0724-6209 